\title{
Follow-up standards and treatment targets in rheumatoid arthritis: results of a questionnaire at the EULAR 2008
}

\author{
Monika Schoels, ${ }^{1}$ Daniel Aletaha, ${ }^{2}$ Josef S Smolen, ${ }^{1,2}$ Johannes W J Bijlsma, ${ }^{3}$ Gerd \\ Burmester, ${ }^{4}$ Ferdinand C Breedveld, ${ }^{5}$ Maurizio Cutolo, ${ }^{6}$ Bernard Combe, ${ }^{7}$ Maxime \\ Dougados, ${ }^{8}$ Paul Emery, ${ }^{9}$ Joachim Kalden, ${ }^{10}$ Edward C Keystone, ${ }^{11}$ Tore K Kvien, ${ }^{12}$ \\ Emilio Martin-Mola, ${ }^{13}$ Carlomaurizio Montecucco, ${ }^{14}$ Maarten De Wit ${ }^{15}$
}

\begin{abstract}
- Additional data are published online only at http://ard.bmj. com/content/vol69/issue3

For numbered affiliations see end of article

Correspondence to

Dr Josef S Smolen, Division of Rheumatology, Department of Medicine 3, Medical University of Vienna, Waehringer Guertel 18-20, A-1090 Vienna, Austria; josef.smolen@wienkav.at; josef. smolen@meduniwien.ac.at
\end{abstract}

Accepted 6 April 2009 Published Online First 22 April 2009

\begin{abstract}
Background Therapeutic approaches to rheumatoid arthritis (RA) have undergone significant changes. The importance of tight control and early treatment, rapidly altered if goals are not achieved, is supported by evidence. However, it is unknown to what extent these insights are accepted by practitioners in clinical practice. Objective To obtain information about standard follow-up and treatment practices, and rheumatologists' aims in the care of patients with RA.
\end{abstract}

Methods A survey conducted at the 2008 EULAR Congress.

Results Most specialists, who were mainly from Europe and Latin America, were well-informed about recent concepts: two-thirds specified remission as a major goal. The experts attempted to reach treatment aims within 12-14 weeks, altering treatment otherwise. Disease activity assessment by composite measures is performed by a majority, although one-third preferentially relied upon their judgment.

Conclusion These results suggest the acceptance of ambitious treatment concepts in practice. Although voluntary surveys have limitations, the answers reflect widespread adoption of desirable standards of care.

\section{INTRODUCTION}

During the current decade, rheumatologists have witnessed a series of major developments in the treatment of rheumatoid arthritis (RA), including new treatments ${ }^{1}$ which allow one to aim for stringent targets, including remission. ${ }^{2}$ Outcomes assessment has also been advanced and become easy to use in clinical practice, ${ }^{3-5}$ allowing assessment of disease activity, response to treatment and categorisation of disease activity states.

Strategic trials defining the effect of rapid switching of treatment if response is insufficient using regular disease activity assessments ${ }^{6-8}$ have fostered tight control and targeting of low disease activity or remission by respective algorithms. ${ }^{9}$

Paradigm changes were also seen in the preceding decade, when early diagnosis and early institution of disease-modifying antirheumatic drugs were in focus. ${ }^{10} 11$ However, the transformation of insights on early arthritis into clinical practice has lagged behind the research progress as seen upon surveying rheumatologists. ${ }^{12}$

It is currently unknown to what extent the assessment of disease activity is performed in daily practice, since obtaining composite disease activity indices may not be feasible routinely and, therefore, assessments focusing only on patient-reported outcomes may be preferable. ${ }^{13}$ There is also insufficient information as to whether tight control and rapid switching of treatment have translated into daily practice.

To examine these issues, we performed a survey among doctors caring for patients with RA. The results of this survey are presented in this report.

\section{METHODS}

\section{Preparation of the survey}

A questionnaire for self-completion using a personal computer was designed. The survey involved nine questions dealing with the monitoring of, and treatment aims for, RA in clinical practice. For details please see online supplementary information. The questions and predefined potential answers were compiled by a steering committee comprising 12 rheumatologists and one patient with RA. They were then transformed into a computerised chart. The survey was performed at the Annual European Congress of Rheumatology in Paris, 2008.

All data analyses were performed using SPSS version 15.0 (SPSS, Chicago, Illinois, USA).

\section{RESULTS}

\section{Demographics of participants}

At the conference, 1044 participants (mostly from Europe and Latin America ( 40\%), but also other countries, such as $2 \%$ from USA) completed the survey; 1001 of whom indicated that they regularly treat patients with RA. For reasons of simplicity, we will focus the analyses primarily on the results obtained from surveying the 870 rheumatologists (including rheumatology trainees) on the items displayed in online supplementary table 1. The professional characteristics are detailed in the supplementary file (mostly they were hospital-based rheumatologists).

\section{Routine assessments}

Individual measures of disease activity and composite indices

The assessment practice of individual measures of disease activity and the mean frequencies of annual assessments are presented in figure $1 \mathrm{~A}, \mathrm{~B}$. 
Assessment of physical function and quality of life

A total of $80.2 \%$ of respondents said that they used the Health Assessment Questionnaire Disability Index; the greatest proportion of them (29.1\%) used it every 3 months (supplementary figure 1) with an estimated number of 1.9 annual assessments. The SF-36 was used by fewer rheumatologists $(50.7 \%)$ and if so, then less frequently with a mean of 1.1 times a year.

\section{Composite indices}

Among the rheumatologists, $45.6 \%$ stated that they used the 28 joint count Disease Activity Score (DAS28) at least every 3 months, while only $13.8 \%$ did not employ it at all (figure 1B). The Simplified Disease Activity Index (SDAI) or the Clinical Disease Activity Index (CDAI) was used by $16.3 \%$ at least every 3 months. Mean annual assessment frequencies were 2.5 for DAS/DAS28 and 1.1 for SDAI/CDAI overall and $2.8 \pm 1.3$ for DAS/ DAS28 and $1.2 \pm 1.5$ for SDAI/CDAI among score users. Among all respondents, 71 worked in the UK or Germany where the evaluation of the DAS28 is reimbursed; significantly fewer of them did not use composite scores at all $(5.6 \%$ vs $14.5 \%$ in all other countries; $\mathrm{p}=0.046$ ). Thus, reimbursement appears to increase the proportion of people using composite scores by almost $10 \%$.

\section{Imaging}

Radiological follow-up was performed every $1-2$ years by $69.5 \%$ of the rheumatologists (figure 1C), whereas ultrasound and MRI are not employed in routine practice by the vast majority.

\section{Therapeutic aims and strategies}

Participants had to rate their agreement with certain statements on a numerical rating scale from 10 (fully approve) to 1 (fully disapprove).

\section{Major treatment aims}

A detailed list of possible answers and respective frequencies of choices made for the question: "What is your major treatment aim for your patients with RA?", is outlined in table 1 (A) (more than one answer was allowed).

Most rheumatologists (67.9\%) defined their major treatment target for patients with RA to be clinical remission measured by a composite index. Also among non-rheumatologists, clinical remission was the number one response (table $1(\mathrm{~A})$ ). Users of composite indices showed a clear trend toward more ambitious treatment goals than non-users.

Of interest, management in hospital practices (academic and non-academic) was very similar to that in office practices (data not shown).

\section{Assessment of treatment response}

A total of $59.1 \%$ judged the presence of a clinical state as important, while $67.6 \%$ used the percentage improvement or absolute improvement of composite scores to evaluate response. Nevertheless, among these latter rheumatologists, $54.3 \%$ indicated that they additionally relied on judging clinical state.
A

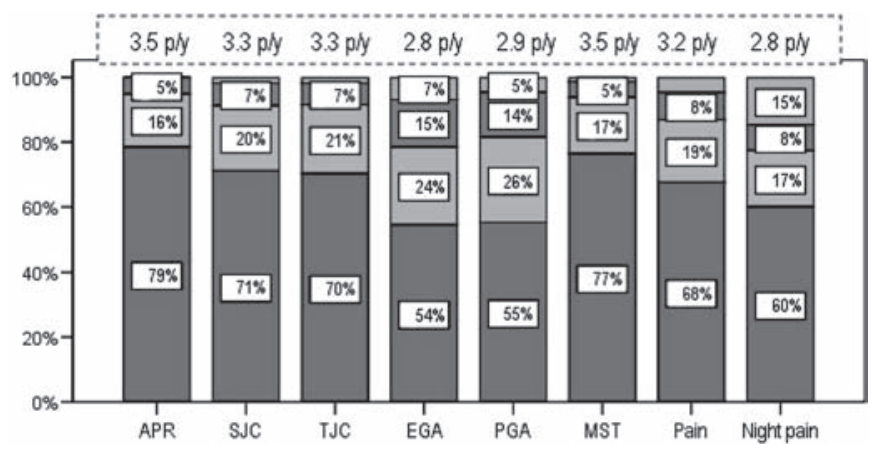

C

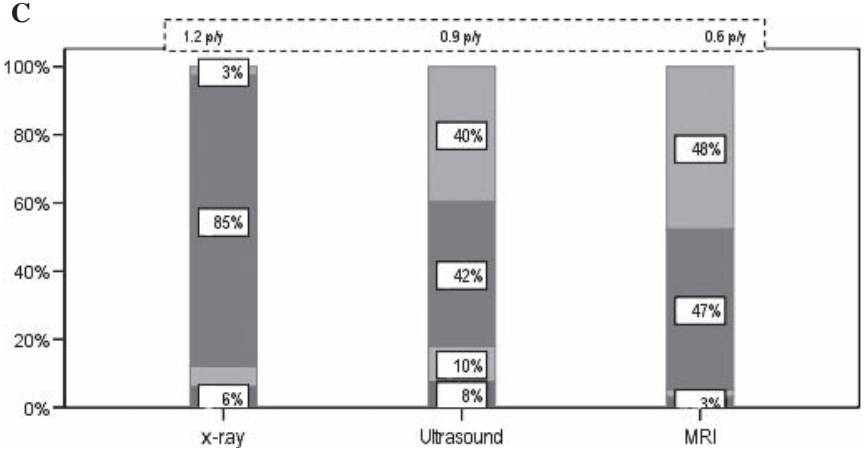

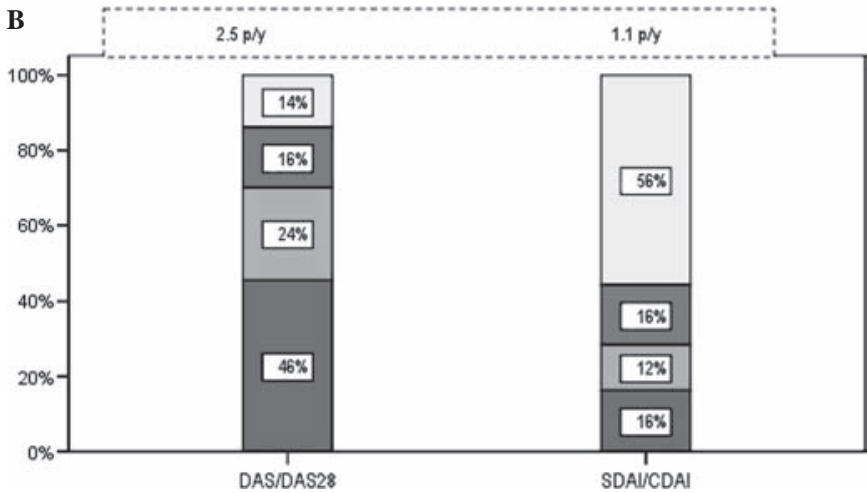

D

Error bars show $95.0 \% \mathrm{Cl}$ of mean

Lack of time is the key obstacle for implementing tight control in practice

Tight control of disease activity is feasible in routine practice

Tight control of disease activity substantially improves long-term outcomes

A clear targets exists to indicate successful control of disease progression

I am using a clear target to define successful control of disease progression

It would be good to have internationally defined guidelines for

treatment targets monitoring and treatment intensity

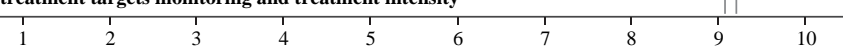

Figure 1 Frequency of assessments. Bars represent percentages of rheumatologists who employed or used the respective assessments "at least every 3 months" (red bars), "every 4-6 months" (green bars), less frequently than every 6 months (blue bars; combined results of the three options "every 6-9 months", "every 1-2 years", "as mandated by authorities") and "do not use at all" (grey bars). Average frequencies of respective assessments per year ( $\mathrm{p} / \mathrm{y})$ are specified above the bars. (A) Proportions of rheumatologists who evaluated, acute phase reactants (APR), swollen joint count (SJC), tender joint count (TJC), evaluator global assessment (EGA), patient global assessment (PGA), morning stiffness (MST), pain and night pain, within the indicated periods. (B) Use of composite indices: percentages of rheumatologists who assessed their patients by composite scores within the indicated period. The average annual frequencies of the Disease Activity Score (DAS) and Simplified Disease Activity Index (SDAI)/ Clinical DAI (SDAI/CDAI) assessments are shown above the bars. (C) Proportion of rheumatologists who employed the various imaging modalities within the indicated periods. (D) Results of analyses of numerical rating scales (means \pm SD) on the agreement with the statements cited above; the scale ranged from $1=$ "I strongly disagree" to $10=$ "I strongly agree". 
Table 1 Treatment aims and strategies

\begin{tabular}{|c|c|c|}
\hline \multirow[b]{2}{*}{ Question } & \multicolumn{2}{|l|}{ Response rate $(\%)$} \\
\hline & $\begin{array}{l}\text { Rheumatologists } \\
(\mathrm{n}=870)\end{array}$ & $\begin{array}{l}\text { Other } \\
(n=131)\end{array}$ \\
\hline \multicolumn{3}{|l|}{ (A) Treatment aims of rheumatologists } \\
\hline $\begin{array}{l}\text { Clinical remission (measured using a } \\
\text { composite index) }\end{array}$ & 67.9 & 42.7 \\
\hline Patient satisfaction with response & 54.7 & 42.0 \\
\hline No structural progression & 54.4 & 33.6 \\
\hline No functional deterioration & 46.7 & 29.8 \\
\hline Prevention of disability & 42.6 & 38.2 \\
\hline $\begin{array}{l}\text { Low disease activity (measured using a } \\
\text { composite score) }\end{array}$ & 34.9 & 27.5 \\
\hline Good clinical response by my own judgment & 34.8 & 27.5 \\
\hline $70 \%$ Improvement of clinical activity & 30.8 & 22.1 \\
\hline $50 \%$ Improvement of clinical activity & 21.0 & 24.4 \\
\hline $\begin{array}{l}\text { Moderate disease activity (measured } \\
\text { using a composite index) }\end{array}$ & 8.5 & 13.0 \\
\hline Any type of response & 7.1 & 13.0 \\
\hline $20 \%$ Improvement of clinical activity & 5.5 & 8.4 \\
\hline Other & 1.0 & 3.8 \\
\hline Do not know & 0.5 & 6.1 \\
\hline \multicolumn{3}{|l|}{ (B) Assessment of treatment success } \\
\hline $\begin{array}{l}\text { Percentage improvement or absolute } \\
\text { improvement by continuous disease activity } \\
\text { indices (eg, DAS28, SDAI) }\end{array}$ & 67.6 & 45.8 \\
\hline $\begin{array}{l}\text { I judge the presence of a clinical state (eg, } \\
\text { high or low disease activity) }\end{array}$ & 59.1 & 51.1 \\
\hline Traditional ACR response criteria & 34.7 & 41.2 \\
\hline Do not know & 0.5 & 6.9 \\
\hline Other & 2.6 & 4.6 \\
\hline \multicolumn{3}{|l|}{ (C) Reasons for the modification of treatment } \\
\hline Persistently high disease activity & 76.4 & 58.8 \\
\hline $\begin{array}{l}\text { Significant radiographic progression } \\
\text { (irrespective of clinical state) }\end{array}$ & 63.8 & 49.6 \\
\hline Patient-reported difficulties with daily activities & 52.0 & 58.0 \\
\hline Persistently moderate disease activity & 49.8 & 29.8 \\
\hline Patient dissatisfaction with response & 48.9 & 40.5 \\
\hline Not reaching remission & 42.3 & 23.7 \\
\hline Do not know & 0.7 & 7.6 \\
\hline
\end{tabular}

Indicated are the percentages of respondents to each question, separately for

rheumatologists and non-rheumatologists.

ACR, American College of Rheumatology; DAS28, 28 joint count Disease Activity Score; SDAl, Simplified Disease Activity Index.

\section{Treatment modification to reach target}

Persistently high disease activity $(76.4 \%)$, significant radiographic progression $(63.8 \%)$ and patient-reported difficulties with daily activities $(52.0 \%)$ were the main reasons for modifying treatment (table $1(\mathrm{C})$ ). Tight control was most strongly judged to improve long-term outcome (mean 9.5 points on a 10-point scale; figure 1D).

\section{Additional analyses}

Additional analyses on respondents who relied upon their own judgment and responses of non-rheumatologists are shown in the online supplementary file.

\section{DISCUSSION}

This survey among almost 900 rheumatologists provides insights into the way patients with RA are followed up in routine practice. Importantly, the vast majority of the rheumatologists indicated that they assess core set variables and composite indices routinely in their patients, usually every 3 months.

When asked for their therapeutic aims, two-thirds indicated that remission using a composite index was their major treatment target, followed by patient satisfaction. More than onethird of the rheumatologists relied on their own judgment of clinical response and, not surprisingly, these used composite indices less frequently than the remainder.

Interestingly, the 131 non-rheumatologists answering the survey gave overall similar responses to those of the rheumatologists and only used control examinations less frequently.

The major question that arises from the results of this survey, which to our knowledge is the first large one of its kind, relates to the reliability of the responses: are the answers a true reflection of the participants' practice or are they merely a reflection of their perception of how patients should best be followed up and treated? Indeed, there are some internal consistencies which suggest that the results may reflect practice: users of composite disease activity indices aimed at more ambitious therapeutic goals significantly more often than rheumatologists who did not primarily use composite scores; the mean of 12-14-week lag period for the decision to switch traditional or biological disease-modifying antirheumatic drugs, respectively, is in line with ambitious therapeutic aims; among doctors originating from countries where reimbursement is offered for obtaining composite indices, the proportion of score users was higher than elsewhere. However, even if the data did not reflect true practice but merely perception of best practice, the results of the survey indicate that the paradigm shift has transpired into clinical practice at least by awareness.

There are several limitations to this study. First, this was only a survey and the results might differ from actual practice. However, the data at least represent the views of participants and can serve as a benchmark on how to approach care of patients with RA in clinical practice; the data also suggest that participants may follow this strategy at least in some of their patients. Second, the data reflect the views of the participants in the survey and not necessarily the general view of rheumatologists; rheumatologists who come to conferences may be particularly interested in the newest developments. Third, academic departments may be over-represented in this survey; however, the data at the least speak the language of the respondents who subsequently may also influence other rheumatologists' views. Fourth, as the survey involved participants of the Annual European Congress, it might be seen as not sufficiently reflecting rheumatologists from other regions; however, about $55 \%$ of the respondents were from outside Europe, particularly Latin America (though only $2 \%$ from the USA) and their responses were similar to those of European survey participants (data not shown). Finally, this questionnaire was designed by expert opinion and has not been validated; however, it was compiled by a committee of 12 rheumatologists and a patient experienced in clinical studies and went through several discussion rounds before finalisation.

The high penetration of the need for tight control examinations using composite indices and remission as therapeutic goal may be surprising but takes account of the many recent publications on the importance of these goals. ${ }^{67914}$ Nevertheless, about onethird of the rheumatologists trusted their own judgment and saw patient satisfaction as the major aim, a less effective approach than score-mediated tight control. ${ }^{6}$ It would be interesting to see the results of their patient care compared with those of others, but this is not within the realm of such a study. Nevertheless, the overall results of this survey indicate that the time may be near when rheumatologists will compare the results of their own practice with those of others, benchmarking the care of RA (for example using computerised databases such as CARAbase ${ }^{15}$ ).

It will be of interest to repeat this survey in the same respondents as well as re-perform it at future EULAR congresses. Also, similar surveys might be valuable nationally to learn about the 
penetration of current paradigms and potential differences in care for RA among different countries or healthcare systems.

In conclusion, the data obtained in this survey suggest that most rheumatologists are aware of the need to follow-up patients tightly using composite scores and to aim for remission as a therapeutic goal, and they adopt this practice. This is a reassuring result and it is to be hoped that the survey responses are truly adhered to in the care of all patients with RA around the world.

Author affiliations ${ }^{1} 2$ nd Department of Medicine, Centre for Rheumatic Diseases, Hietzing Hospital, Vienna, Austria

${ }^{2}$ Division of Rheumatology, Department of Internal Medicine 3, Medical University of Vienna, Austria

${ }^{3}$ Department of Rheumatology \& Clinical Immunology, University Medical Centre, Utrecht, The Netherlands

${ }^{4}$ Department of Rheumatology and Clinical Immunology, Humboldt University, Charite Hospital, Berlin, Germany

${ }^{5}$ Department of Rheumatology, Leiden University Medical Centre, Leiden, The Netherlands

${ }^{6}$ Research Laboratory and Academic Clinical Unit of Rheumatology, Department of Internal Medicine, University of Genova, Italy

${ }^{7}$ Service d'Immuno-Rhumatologie, Montpellier I University, Lapeyronie Hospital, Montpellier, France

${ }^{8}$ Department of Rheumatology B, René Descartes University, Cochin Hospital, Paris, France

${ }^{9}$ Academic Unit of Musculoskeletal Disease, University of Leeds, UK

${ }^{10}$ Department of Internal Medicine III, Friedrich-Alexander University, Erlangen, Germany

${ }^{11}$ Mount Sinai Hospital, Toronto, Canada

${ }^{12}$ Department of Rheumatology, Diakonhjemmet Hospital, Oslo, Norway

${ }^{13}$ La Paz Hospital, Madrid, Spain

${ }^{14}$ Department of Rheumatology, University of Pavia, IRCCS Policlinico S Matteo, Pavia, Italy

${ }^{15}$ EULAR Standing Committee of People with Arthritis/Rheumatism in Europe, Zurich, Switzerland

Funding The study was supported by an unrestricted grant from Abbott.

Competing interest Representatives of the company attended the initial meeting, but had no active participation or influence on the decision-making regarding the questions. In addition, none of the questions related to the use of particular treatments. The analyses were performed at the Medical University of Vienna. The handling editor was D T Boumpas.

Provenance and peer review Not commissioned; externally peer reviewed.

\section{REFERENCES}

1. Smolen JS, Aletaha D, Koeller M, et al. New therapies for treatment of rheumatoid arthritis. Lancet 2007;370:1861-74.

2. Emery P, Breedveld FC, Hall S, et al. Comparison of methotrexate monotherapy with a combination of methotrexate and etanercept in active, early, moderate to severe rheumatoid arthritis (COMET): a randomised, double-blind, parallel treatment trial. Lancet 2008;372:375-82

3. van Gestel AM, Haagsma CJ, van Riel PL. Validation of rheumatoid arthritis improvement criteria that include simplified joint counts. Arthritis Rheum 1998;41:1845-50

4. Aletaha $\mathbf{D}$, Smolen JS. The definition and measurement of disease modification in inflammatory rheumatic diseases. Rheum Dis Clin North Am 2006;32:9-44, vii.

5. Smolen JS, Breedveld FC, Schiff MH, et al. A simplified disease activity index for rheumatoid arthritis for use in clinical practice. Rheumatology (Oxford) 2003;42:244-57.

6. Grigor C, Capell H, Stirling A, et al. Effect of a treatment strategy of tight control for rheumatoid arthritis (the TICORA study): a single-blind randomised controlled trial. Lancet 2004;364:263-9.

7. Goekoop-Ruiterman YP, de Vries-Bouwstra JK, Allaart CF, et al. Clinical and radiographic outcomes of four different treatment strategies in patients with early rheumatoid arthritis (the BeSt study): a randomized, controlled trial. Arthritis Rheum 2005:52:3381-90.

8. Verstappen SM, Jacobs JW, van der Veen MJ, et al. Intensive treatment with methotrexate in early rheumatoid arthritis: aiming for remission. Computer Assisted Management in Early Rheumatoid Arthritis (CAMERA, an open-label strategy trial). Ann Rheum Dis 2007;66:1443-9.

9. Smolen JS, Sokka T, Pincus T, et al. A proposed treatment algorithm for rheumatoid arthritis: aggressive therapy, methotrexate, and quantitative measures. Clin Exp Rheumatol 2003:21 (5 Suppl 31):S209-10.

10. van der Heide A, Jacobs JW, Bijlsma JW, et al. The effectiveness of early treatment with "second-line" antirheumatic drugs. A randomized, controlled trial. Ann Intern Med 1996;124:699-707.

11. Lard LR, Visser H, Speyer I, et al. Early versus delayed treatment in patients with recent-onset rheumatoid arthritis: comparison of two cohorts who received different treatment strategies. Am J Med 2001;111:446-51.

12. Aletaha D, Eberl G, Nell VP, et al. Attitudes to early rheumatoid arthritis: changing patterns. Results of a survey. Ann Rheum Dis 2004;63:1269-75.

13. Pincus $\mathbf{T}$, Yazici Y, Bergman $M$, et al. A proposed continuous quality improvement approach to assessment and management of patients with rheumatoid arthritis without formal joint counts, based on quantitative routine assessment of patient index data (RAPID) scores on a multidimensional health assessment questionnaire (MDHA0). Best Pract Res Clin Rheumatol 2007;21:789-804.

14. Möttönen $\mathbf{T}$, Hannonen P, Leirisalo-Repo $\mathrm{M}$, et al. Comparison of combination therapy with single-drug therapy in early rheumatoid arthritis: a randomised trial. FIN-RACo trial group. Lancet 1999;353:1568-73.

15. Stamm TA, Aletaha D, Pflugbeil S, et al.The use of databases for quality assessment in rheumatoid arthritis. Clin Exp Rheumatol 2007;25:82-5. 


\section{Corrections}

The department of one of the authors who co-authored all of the below papers has found that the affiliations were not correct. The correct affiliations for Professor P Emery, for all of the below articles, are: ${ }^{1}$ Section of Musculoskeletal Disease, Leeds Institute of Molecular Medicine, University of Leeds; ${ }^{2}$ NIHR Leeds Musculoskeletal Biomedical Research Unit, Leeds Teaching Hospitals Trust, Leeds, UK.

1. Keystone E, Emery P, Peterfy CG, et al. Rituximab inhibits structural joint damage in patients with rheumatoid arthritis with an inadequate response to tumour necrosis factor inhibitor therapies. Ann Rheum Dis 2009;68:216-21.

2. Doward LC, McKenna SP, Whalley D, et al. The development of the L-OoL: a quality-of-life instrument specific to systemic lupus erythematosus. Ann Rheum Dis 2009;68:196-200.

3. Potter C, Hyrich KL, Tracey A, et al. Association of rheumatoid factor and anticyclic citrullinated peptide positivity, but not carriage of shared epitope or PTPN22 susceptibility variants, with anti-TNF response in RA. Ann Rheum Dis 2009;68:69-74.

4. Smolen JS, Han C, van der Heijde DM, et al.; Active-Controlled Study of Patients Receiving Infliximab for the Treatment of Rheumatoid Arthritis of Early Onset (ASPIRE) Study Group. Radiographic changes in rheumatoid arthritis patients attaining different disease activity states with methotrexate monotherapy and infliximab plus methotrexate: the impacts of remission and tumour necrosis factor blockade. Ann Rheum Dis 2009;68:823-7.

5. Buch MH, Boyle DL, Rosengren S, et al. Mode of action of abatacept in rheumatoid arthritis patients having failed tumour necrosis factor blockade: a histological, gene expression and dynamic magnetic resonance imaging pilot study. Ann Rheum Dis 2009;68:1220-7.

6. Emery P, Van Vollenhoven R, Ostergaard M, et al. Guidelines for initiation of antitumour necrosis factor therapy in rheumatoid arthritis: similarities and differences across Europe. Ann Rheum Dis 2009;68:456-9.

7. Bejarano V, Conaghan PG, Proudman SM, et al. Long-term efficacy and toxicity of ciclosporin A in combination with methotrexate in poor prognosis rheumatoid arthritis Ann Rheum Dis 2009;68:761-3.

8. Rudwaleit M, Landewé R, van der Heijde D, et al. The development of Assessment of SpondyloArthritis international Society classification criteria for axial spondyloarthritis (part I): classification of paper patients by expert opinion including uncertainty appraisal. Ann Rheum Dis 2009;68:770-6.

9. Bennett AN, Marzo-Ortega H, Emery P, et al.; Leeds Spondyloarthropathy Group. Diagnosing axial spondyloarthropathy. The new Assessment in SpondyloArthritis international Society criteria: MRI entering centre stage. Ann Rheum Dis 2009;68:765-7.

10. Marzo-Ortega H, McGonagle D, O'Connor P, et al. Baseline and 1-year magnetic resonance imaging of the sacroiliac joint and lumbar spine in very early inflammatory back pain. Relationship between symptoms, HLA-B27 and disease extent and persistence. Ann Rheum Dis 2009;68:1721-7.

11. Gilworth G, Emery P, Gossec L, et al. Adaptation and cross-cultural validation of the rheumatoid arthritis work instability scale (RA-WIS). Ann Rheum Dis 2009;68:1686-90.

12. Gilworth G, Emery P, Gossec L, et al. Adaptation and cross-cultural validation of the RA-WIS (Work Instability Scale). Ann Rheum Dis 2009;68:1686-90.

13. Jarrett SJ, Sivera F, Cawkwell LS, et al. MRI and clinical findings in patients with ankylosing spondylitis eligible for anti-tumour necrosis factor therapy after a short course of etoricoxib. Ann Rheum Dis 2009;68:1466-9.

14. Haugeberg G, Conaghan PG, Quinn $\mathrm{M}$, et al. Bone loss in patients with active early rheumatoid arthritis: infliximab and methotrexate compared with methotrexate treatment alone. Explorative analysis from a 12-month randomised, double-blind, placebo-controlled study. Ann Rheum Dis 2009;68:1898-901.

15. Genovese MC, Breedveld FC, Emery P, et al. Safety of biological therapies following rituximab treatment in rheumatoid arthritis patients. Ann Rheum Dis 2009;68:1894-7

16. Kekow J, Moots RJ, Emery P, et al. Patient-reported outcomes improve with etanercept plus methotrexate in active early rheumatoid arthritis and the improvement is strongly associated with remission: the COMET trial. Ann Rheum Dis 2010;69:222-5

17. Furst DE, Keystone EC, Fleischmann R, et al. Updated consensus statement on biological agents for the treatment of rheumatic diseases, 2009. Ann Rheum Dis 2010;69(Suppl 1):i2-29.

18. Freeston JE, Wakefield RJ, Conaghan PG, et al. A diagnostic algorithm for persistence of very early inflammatory arthritis: the utility of power Doppler ultrasound when added to conventional assessment tools. Ann Rheum Dis 2010;69:417-9.

19. Jones $\mathbf{E}$, Churchman SM, English A, et al. Mesenchymal stem cells in rheumatoid synovium: enumeration and functional assessment in relation to synovial inflammation level. Ann Rheum Dis 2010;69:450-7.

20. Alten RE, Zerbini C, Jeka S, et al. Efficacy and safety of pamapimod in patients with active rheumatoid arthritis receiving stable methotrexate therapy. Ann Rheum Dis 2010;69:364-7.
21. Machold KP, Landewé R, Smolen JS, et al. The Stop Arthritis Very Early (SAVE) trial, an international multicentre, randomised, double-blind, placebo-controlled trial on glucocorticoids in very early arthritis. Ann Rheum Dis 2010;69:495-502.

22. Schoels M, Knevel R, Aletaha D, et al. Evidence for treating rheumatoid arthritis to target: results of a systematic literature search. Ann Rheum Dis 2010;69:638-43.

23. Smolen JS, Aletaha D, Bijlsma JW, et al.; T2T Expert Committee. Treating rheumatoid arthritis to target: recommendations of an international task force. Ann Rheum Dis 2010;69:631-7.

24. Burr ML, Naseem H, Hinks A, et al.; BIRAC Consortium; YEAR Consortium. PADI4 genotype is not associated with rheumatoid arthritis in a large UK Caucasian population. Ann Rheum Dis 2010;69:666-70.

25. Emery $\mathbf{P}$, Durez P, Dougados $\mathrm{M}$, et al. Impact of T-cell costimulation modulation in patients with undifferentiated inflammatory arthritis or very early rheumatoid arthritis: a clinical and imaging study of abatacept (the ADJUST trial). Ann Rheum Dis 2010;69:510-16.

26. Bennett AN, Rehman A, Hensor EM, et al. The fatty Romanus lesion: a noninflammatory spinal MRI lesion specific for axial spondyloarthropathy. Ann Rheum Dis 2010;69:891-4.

27. Nam JL, Winthrop KL, van Vollenhoven RF, et al. Current evidence for the management of rheumatoid arthritis with biological disease-modifying antirheumatic drugs: a systematic literature review informing the EULAR recommendations for the management of RA. Ann Rheum Dis 2010;69:976-86.

28. Smolen JS, Landewé R, Breedveld FC, et al. EULAR recommendations for the management of rheumatoid arthritis with synthetic and biological disease-modifying antirheumatic drugs. Ann Rheum Dis 2010;69:964-75.

29. Tan RJ, Gibbons LJ, Potter C, et al.; BRAGGSS. Investigation of rheumatoid arthritis susceptibility genes identifies association of AFF3 and CD226 variants with response to anti-tumour necrosis factor treatment. Ann Rheum Dis 2010;69:1029-35.

30. Robinson JI, Barrett JH, Taylor JC, et al.; YEAR Consortium; BRAGGSS. Dissection of the FCGR3A association with RA: increased association in men and with autoantibody positive disease. Ann Rheum Dis 2010;69:1054-7.

31. Cohen SB, Keystone E, Genovese MC, et al. Continued inhibition of structural damage over 2 years in patients with rheumatoid arthritis treated with rituximab in combination with methotrexate. Ann Rheum Dis 2010;69:1158-61.

32. Haugeberg G, Bennett AN, McGonagle D, et al. Bone loss in very early inflammatory back pain in undifferentiated spondyloarthropathy: a 1-year observational study. Ann Rheum Dis 2010;69:1364-6.

33. Schoels M, Aletaha D, Smolen JS, et al. Follow-up standards and treatment targets in rheumatoid arthritis: results of a questionnaire at the EULAR 2008. Ann Rheum Dis 2010;69:575-8

34. Eyre S, Flynn E, Martin P, et al. No evidence for association of the KLF12 gene with rheumatoid arthritis in a large UK cohort. Ann Rheum Dis 2010;69:1407-8.

35. Eyre S, Hinks A, Flynn E, et al. Confirmation of association of the REL locus with rheumatoid arthritis susceptibility in the UK population. Ann Rheum Dis 2010;69:1572-3

36. Orozco G, Eyre S, Hinks A, et al.; Wellcome Trust Case Control consortium YEAR Consortium. Association of CD40 with rheumatoid arthritis confirmed in a large UK case-control study. Ann Rheum Dis 2010;69:813-16.

37. Emery $\mathbf{P}$, Durez P, Dougados $M$, et al. Impact of T-cell costimulation modulation in patients with undifferentiated inflammatory arthritis or very early rheumatoid arthritis: a clinical and imaging study of abatacept (the ADJUST trial). Ann Rheum Dis 2010;69:510-16

38. Saleem B, Keen $\mathrm{H}$, Goeb V, et al. Patients with RA in remission on TNF blockers: when and in whom can TNF blocker therapy be stopped? Ann Rheum Dis 2010;69:1636-42.

39. Barkham N, Coates LC, Keen H, et al. Double-blind placebo-controlled trial of etanercept in the prevention of work disability in ankylosing spondylitis. Ann Rheum Dis 2010;69:1926-8.

40. Emery P, Deodhar A, Rigby WF, et al. Efficacy and safety of different doses and retreatment of rituximab: a randomised, placebo-controlled trial in patients who are biological naive with active rheumatoid arthritis and an inadequate response to methotrexate (Study Evaluating Rituximab's Efficacy in MTX iNadequate rEsponders (SERENE)). Ann Rheum Dis 2010;69:1629-35.

41. Dixon WG, Hyrich KL, Watson KD, et al.; BSRBR Control Centre Consortium; British Society for Rheumatology Biologics Register. Influence of anti-TNF therapy on mortality in patients with rheumatoid arthritis-associated interstitial lung disease: results from the British Society for Rheumatology Biologics Register. Ann Rheum Dis 2010;69:1086-91. 